\title{
Avaliação da fluoretação da água do sistema \\ de abastecimento público na Il ha de São Luís, Maranhão, Brasil
}

\author{
Evaluation of fluoride levels in the public water supply \\ in São Luis Island, M aranhão State, Brazil
}

${ }^{1}$ Departamento de

Odontologiall, Faculdade deOdontologia, UniversidadeFederal do

Maranhão. Av. dos

Portugueses $s / n$,

Departamento de

OdontologialI, Campus

Universitário do Bacanga.

65085-580 São Luis MA.

cadidjadayane@yahoo.com.br.

${ }^{2}$ Curso de Ciências

Aquáticas, Universidade

Federal do M aranhão.

Abstract The aim of the present study was to evaluate the fluoride levels in public water supply in São Luís island, M aranhão State, Brazil, during the month of $\mathrm{O}$ ctober of 2006. A stratification sampling was applied, considering thewater treatment station (06) and the different districts (46). For fluoride analysis it was used a specific ion electrode. The fluoride concentration varied for 0.05 to $0.84 \mathrm{ppm}$. Only one water treatment station (Italuís) presented an ideal concentration of fluoride. It was concluded that the fluoride levels need adjustments, evidencing that it is essential an external control for monitoring of those levels in public water supply of São Luis.

Key words Dental caries, Fluoridation, Water
Resumo 0 objetivo deste estudo foi avaliar os níveis de flúor na água de abastecimento público da I lha de São Luís (M A). Aplicou-seuma amostragem estratificada, considerando-se as estações de tratamento de água (06) e os bairros abastecidos (46). A análise dos teores de flúor na água foi feita através de um eletrodo específico. A concentração nas amostras variou de 0,05 a 0,84 ppm de flúor. A penasuma estação de tratamento (Italuís) apresentou-se dentro do limite aceitável de fluoretação. A fluoretação da água de abastecimento público na Ilha de São Luís necessita de ajustes para se obter prevenção da cárie, evidenciando a importância de um controle externo para avaliação dos teores de flúor.

Palavras-chave Cárie dentária, Fluoretação, Água 
Introdução

A ampla utilização do flúor tem sido apontada como a principal razão do declínio da prevalência de cárie na população mundial11-3.

Os percentuais médios de redução de cárie de algumas cidades brasileiras, como Belo H orizonte - M G $(44,6 \%)^{4}$, Barretos - SP $(55 \%)^{5}$, Campinas - SP $(57 \%)^{6}$, Goiânia - GO $(57,1 \%)^{7}$ e Piracicaba - SP $(79 \%)^{8}$, evidenciaram reduções consideráveis no índice de cárie da população após a adoção da fluoretação da água de abastecimento público (FAAP).

A fluoretação em sistemas públicos de abastecimento deágua no Brasil tornou-seuma obrigatoriedade através da Lei $\mathrm{n} 06.050$ de 24 demaio de 1974, regulamentada pelo Decreto Federal no 76.872 de 22 de dezembro de 1975 e através da Portaria no 635/BSB de 26 de dezembro de 1975 do M inistério da Saúde9.

Por regulamentação, os limites de concentração do íon fluoreto na água de abastecimento devem ser uma função da média das temperaturas máximas do ar. Assim, os teores de flúor considerados "ótimos" para a prevenção da cárie dental devem ter, na maior parte do território brasileiro, 0,7 mg de flúor por litro, podendo variar em $0,1 \mathrm{mg}$ para mais ou para menos ${ }^{10}$.

Em termos de abrangência coletiva, a fluore tação da água de abastecimento público é considerada o método de prevenção da cárie dentária mais efetivo, representando uma das principaise mais importantes medidas de saúde pública ${ }^{11} \mathrm{e}$ ainda o método preventivo à cárie dental demaior equidade, adesão, melhor custo-efetividade e segurança ${ }^{12-14}$.

Para manutenção dos níveis adequados do flúor, éfundamental que, além do controle interno do abastecedor, seja feito um heterocontrole por parte das instituições do Estado ${ }^{15}$.

A Ilha de São Luís tem temperatura média anual em torno de $30^{\circ} \mathrm{C}$, é abastecida por cinco diferentesEstações deTratamento deÁgua(ETA). E, em fevereiro de 2006, três delas passaram a ter implantada a fluoretação da água de abastecimento público.

Considerando que a fluoretação da água de abastecimento público foi implantada na I lha de São Luís e que os níveis de flúor precisam ser acompanhados para ter efeito anticárie e sem oferecer risco à fluorose, torna-se necessária a avaliação dos teores de flúor na água, através de um heterocontrole. Sendo assim, o objetivo do presente estudo foi analisar os níveis de fluoretação da água executados nas diferentes ETA que abastecem a Ilha de São Luís durante o mês de outubro de 2006.

Material emétodos

Inicialmente, foi realizado contato com a Companhia de Águas e Esgotos do M aranhão (CAE$\mathrm{MA}$ ), responsável pelo tratamento da água de abastecimento público da I lha de São Luís, a fim de se obter as informações necessárias ao trabaIho, como a data de início da fluoretação ea divisão dos bairros de acordo com as Estações de Tratamento de Água (ETA).

Ao todo, seis estações de tratamento abastecem a Il ha de São Luís, sendo elas: I taluís, Olho D'Água, Paciência, Sacavém, Cururuca eSistema de São José de Ribamar, que abastecem um total de 54 bairros, além do município, São José de Ribamar.

De acordo com informações coletadas junto àquela companhia, não existe flúor de forma natural nas águas dos rios que abastecem asETA. Para tanto, o composto fluossilicato de sódio $\left(\mathrm{Na}_{2} \mathrm{Si}_{6}\right)$ é aplicado diretamente na água através de bomba dosadora não automática (ETA Italuís) e um aparelho saturador (ETA Sacavém e Paciência). 0 controle de qualidade é do tipo colorimétrico, fazendo uso deum aparel ho colorímetro microprocessado. 0 mesmo é realizado por um técnico-químico nas ETA, de forma diária e num intervalo de duas em duas horas, sendo o controle noturno realizado pelos operadores da bomba dosadora e do saturador. Já na rede de distribuição, o controleaconteceuma vez ao dia durante a manhã, tendo os níveis de flúor relatados pela CAEM A em $0,7 \mathrm{mg} / \mathrm{L}$.

Três ETA apresentam nível de flúor relatado pelo CAEMA em torno de $0,7 \mathrm{mg} / \mathrm{L}$, sendo elas: ETA Italuís, que abastece os bairros São Francisco, Ponta da Areia, Ponta do Farol, Renascença I ell, Vinhais, Bequimão, Angelin, Cohama, Altos do Calhau, M aranhão N ovo, I pase, Recanto dos Vinhais, Cohafuma, Ilhinha, Porto do Itaqui, Jaracati e Olho D'Água, totalizando 685.930 habitantes; ETA Paciência, abastecendo Cohab I, II, III, IV, Cohatrac I, II, III elV, um total de151.209 habitantes; ETA Sacavém, com os bairros Centro, Madre Deus, Goiabal, Retiro Natal, M onte Castelo, João Paulo, Liberdade, Floresta, Alto da Boa Vista, Vila Passos, Camboa, Diamante, São Pantaleão, Macaúba, Corea, Tomé de Sousa, Vila Bangu e Apicum, com um total de 113.656 habitantes.

Dentre as que apresentam nível de flúor relatado pela CAEM A como ausente de fluoretação 
estão a ETA Cururuca, responsável pelo Conjunto M aiobão, com 61.384 habitantes, e o Sistema de São José de Ribamar, que abastecea cidade de São José de Ribamar, com 130.448 habitantes.

Com o objetivo de realizar o heterocontrole dos níveis de flúor na água de abastecimento público dallha deSão Luís (M A), aplicou-seuma amostragem estratificada, em quea primeira pré estratificação referiu-se aos sistemas de abastecimento e a segunda, aos bairros participantes de cada ETA. Diante disso, em cada ETA, de acordo com o número de bairros abastecidos, de um a quatro bairros foram sorteados para a realização das coletas, totalizando assim doze bairros. Além desses, um bairro e um município sem a fluoretação da água de abastecimento público também foram avaliados, como controle negativo (M ai obão e São J osé de Ribamar).

Realizou-se, durante o mês de outubro de 2006, uma coleta por semana em cada bairro sorteado. Para isso, foram utilizados frascos de 10 $\mathrm{ml}$ prélavados e etiquetados com a identificação da respectiva ETA, o nome do bairro e a data da coleta. A água coletada, obrigatoriamente, vinha direto do sistema de abastecimento, ou seja, sem passagem por caixa d' água, cisterna ou similar.

O local de coleta em cada bairro foi o mesmo durante todo o trabalho, sendo determinado de acordo com a proximidade ao ponto de parada de ônibus e receptividade das pessoas em cooperar com o fornecimento da água. A coleta foi repetida por mais três vezes, forman do 48 amostras de água fluoretada e oito amostras de água não fluoretada, totalizando 56 amostras. As mesmas foram estocadas em freezer $\left(-22^{\circ} \mathrm{C}\right)$ até 0 momento em que se realizou a análise.

Para a determinação da concentração de íon flúor na água, utilizou-seum eletrodo específico para o flúor (ISE25F/Radiometer Copenhagen), acoplado a um analisador de íons (PH M 240/ Radiometer Copenhagen). Inicialmente, foi feita uma curva de calibração com soluções padrão de 0,05 a 4,0 ppm F. A leitura das amostras foi feita em $\mathrm{mV}$ e transformada em ppm através de uma planilha eletrônica, software Excel (M icrosoft). Contraprovas em $30 \%$ das amostras foram realizadas pelo Laboratório de Bioquímica O ral da Facul dade de 0 dontologia de Piracicaba da Universidade Estadual de Campinas, laboratório de referência nacional em análises dos teores de fluoretos. Para comparação das médias de leituras entre os dois laboratórios, foi aplicado 0 teste t para amostras pareadas.

\section{Resultados}

A Tabela 1 mostra as médias das leituras semanais, durante o mês de outubro de 2006, nos catorze bairros selecionados. Foi encontrado, nos bairros cujas ETA têm adição de flúor, uma variação entre 0,26 a 0,74 ppm deflúor e uma variação entre 0,06 e 0,07 ppm deflúor nos locais avaliados como sem fluoretação. Não foi encontrada diferença entre as leituras de flúor nos dois laboratórios ( $p=0.47)$.

Tabela 1. Concentração de flúor (ppm) na água de abastecimento nos catorze bairros avaliados na Ilha de São Luís (M A) durante o mês de outubro de 2006 (média \pm dp).

\begin{tabular}{|c|c|c|}
\hline Estação de tratamento & Local da coleta & M édia ppm $F( \pm d p) \quad n=4$ \\
\hline \multirow[t]{5}{*}{ Italuís } & P.D' Areia & $0,59( \pm 0,18)$ \\
\hline & A.do Calhau & $0,74( \pm 0,13)$ \\
\hline & Recanto dosVinhais & $0,74( \pm 0,07)$ \\
\hline & Cohafuma & $0,64( \pm 0,12)$ \\
\hline & Jaracati & $0,66( \pm 0,15)$ \\
\hline \multirow[t]{2}{*}{ Paciência } & Cohab III & $0,33( \pm 0,19)$ \\
\hline & Cohatrac IV & $0,26( \pm 0,02)$ \\
\hline \multirow[t]{5}{*}{ Sacavém } & Goiabal & $0,57( \pm 0,13)$ \\
\hline & Retiro Natal & $0,58( \pm 0,08)$ \\
\hline & João Paulo & $0,50( \pm 0,06)$ \\
\hline & Floresta & $0,58( \pm 0,13)$ \\
\hline & Apicum & $0,42( \pm 0,11)$ \\
\hline Cururuca & M aiobão & menor que $0,05 \mathrm{ppm}$ \\
\hline São José de Ribamar & São José de Ribamar & menor que 0,05 ppm \\
\hline
\end{tabular}


Considerando a relação entre a média das temperaturas máximas anuais e os teores deíons fluoretos recomendados pela Portaria no 635/ BSB de 26/12/1975 e sabendo que a temperatura média local éde $30^{\circ} \mathrm{C}$, tem-se $0,6 \mathrm{ppm} F$ como o limite mínimo recomendado para a concentração do íon fluoreto, 0,7 ppm F como nível considerado ótimo e 0,8 ppm F como limite máximo recomendado ${ }^{9}$.

Assim, a análise dos dados das amostras coletadas de forma individual, revel ou que:

a) $53,57 \%$ das amostras registraram nível de fluoretação abaixo do limite permitido (abaixo de 0,6 ppm F);

b) 19,64\% apresentaram o mínimo de fluoretação $(0,6$ ppm F);

c) $14,29 \%$ estavam em nível ótimo; $(0,7$ ppmF);

d) $12,5 \%$ em nível máximo (0,8 ppm F);

e) $0 \%$ acima do limite máximo (acima de 0,8 ppm F).

Ao se avaliar os resultados para cada ETA (Gráfico 1), percebe-se que a I taluís apresentouse dentro do limite aceitável de fluoretação (de 0,6 a 0,8 ppm F), enquanto as ETA Paciência e Sacavém foram classificadas em caráter inaceitável para o fator proteção contra cárie, já que re gistraram valores abaixo do mínimo permitido para tal (abaixo de 0,6 ppm F).

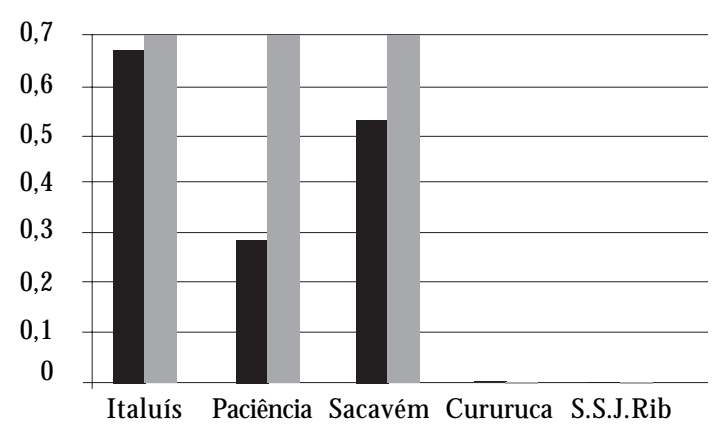

ppmF encontrado ppmf relatado

Gráfico 1. Concentração de fluoreto encontrada nas diferentes estações de tratamento de água em São Luís (MA) em comparação com os teores relatados pela companhia de abastecimento.

\section{Discussão}

A fluoretação da água de abastecimento público (FAAP) é um dos princi pais métodos envolvidos na prevenção da cárie dental, sendo recomendada por inúmeras organizações científicas, sanitárias e políticas9,10,12,15.

Assim, os benefícios da fluoretação da água de abastecimento devem ser assegurados através de um adequado controle de todo o processo de fluoretação, partindo do pressuposto de que não basta somente manter ou acrescentar flúor à água ${ }^{16}$. É imprescindível, nesse aspecto, o cuidado de evitar a insuficiência ou o exagero na adição deflúor, já que, dessa forma, respectivamente, não haverá prevenção à cárie e existirá o risco à fluorose dental ${ }^{17}$.

$N$ as cidades de Pelotas $(R S)^{18}$, durante 24 meses, eN iterói $(R J)^{19}$, durantedoze meses de análise, não foi possível encontrar uma regularidade nos teores de flúor encontrados na água de abastecimento público, tornando clara a necessidade de um heterocontrole para que seja assegurada a prevenção à cárie e evitada a fluorose dental.

De modo semelhante, $53,57 \%$ das amostras coletadas no presente estudo mostraram valores inadequados deflúor, evidenciando um comprometimento dos ben efícios da fluoretação da água de abastecimento público e destacando a importância do heterocontrole para uma manutenção dos valores ideais à efetiva prevenção da cárie.

Essa subfluoretação foi de maneira regular no período de observação, pois foram encontrados baixos valores de desvio padrão (dp) entre as coletas. Diante disso, consideram-se prováveis distorções no manejo das máquinas dosadoras de flúor, devido ao uso de aparelhos não automáticos ou, ainda, no método de controle de qualidade, já que o método colorimétrico não éo mais indicado ${ }^{19,20}$.

Nos locais onde há cobertura de FAAP, $46,43 \%$ das amostras estão dentro de limites aceitáveis, sendo $14,29 \%$ de nível ótimo, $19,64 \%$ de nível mínimo e $12,5 \%$ de nível máximo. Assim, o poder de prevenção à cárie através do flúor oferecido pela água de abastecimento público, além de efetivo, está fora do risco de fluorose dental.

A ETA Italuís (0,67 ppm F) apresentou média dentro do limite aceitável defluoretação, enquanto as ETA Paciência ( 0,29 ppm F) eSacavém (0,53 ppm F) apresentaram valores característicos de subfluoretação. Os teores insignificantes (< que $0,05 \mathrm{ppmF}$ ) de fluoreto encontrados nas ETA Cururuca e o Sistema São José de Ribamar confirmam a ausência de adição de flúor relatada pela companhia de abastecimento. 
Com isso, percebe-se que os bairros periféricos, em geral menosfavorecidos economicamente, são os mais acometidos pela subfluoretação ou ausência de fluoretação da água de abastecimento público na Il ha de São Luís. Assim, a situação éainda mais preocupante, visto que, muitas vezes, essa seria a única forma de obtenção de flúor por tais populações, para as quais este tem importância ainda mais evidente na prevenção da cárie.

\section{Conclusão}

Diante do exposto, pode-se concluir que a fluoretação da água deabastecimento público (FAAP) na Ilha de São Luís necessita de ajustes para que o objetivo maior, a prevenção da cárie, possa ser adequadamente al cançado e, assim, a população receba o que lhe é de direito.

A FAAP na Il ha de São Luís deve ser corretamente implantada e executada em bairros periféricos, mantendo os níveis do íon fluoreto de forma ideal para que torne possível seu efeito anticárie.

Além disso, fica evidente a importância deum heterocontrole para que haja garantia de melhoras na saúde bucal da população.

\section{Colaboradores}

CDS do Carmo elaborou o projeto de pesquisa, realizou as coletas de água, a análise laboratorial dos dados em São Luís e redigiu o artigo. PR Cavalcante participou da análise laboratorial realizada na Universidade Federal do M aranhão. CMC Alves auxiliou nas análises dos resultados e na elaboração do artigo. CCC Ribeiro delineou o projeto, orientou a execução da pesquisa efoi a responsável pelas análises dos dados e revisão crítica do artigo.

\section{Agradecimentos}

Ao Laboratório de Bioquímica Oral da Faculdade de Odontologia de Piracicaba da Universidade Estadual de Campinas, em especial ao Prof.. Dr. JaimeA parecido Cury, pelas leituras das contraprovas realizadas. 


\section{Referências}

1. Marthaller TM. Water fluoridation results in Basel since 1962: health and political implications. J Pub HIth Dent 1996; 56(5 Spec No):265-270.

2. Cutress TW, Coote G, Shu M, Pearce El. Fluoride content of the enamel and dentine of human premolars prior to and following the introduction of fluoridation in New Zealand. Caries Res 1996; 3:204-212.

3. Cury JA, Tenuta LM A, Ribeiro CCC, Paes Leme AF. The importance of fluoride Dentifrices to the current dental caries prevalence in Brazil. Braz Dent J 2004; 15:1-8

4. Oliveira CM B, Assis DF, Ferreira EF. Avaliação da fluoretação da água de abastecimento público de Belo Horizonte, M G, após 18 anos. Revista do Conselho Regional de Odontologia de M inas Gerais 1995; 1:62-66.

5. Viegas Y, Viegas AR. Análise dos dados de prevalência de cárie dental na cidade de Barretos, SP, Brasil, depois de dez anos de fluoretação da água de abastecimento público. Rev. Saude Publica 1985; 4:287-299.

6. Viegas Y, Viegas AR. Análise dos dados de prevalência de cárie dental na cidade de Campinas, SP, Brasil, depois de dez anos de fluoração da água de abastecimento público. Rev. Saude Publica 1974 8:399-409.

7. Freire MCM, Pereira M F, Batista M RS, Barbosa MI, Rosa AGF. Prevalência de cárie e necessidade de tratamento entre escolares de 6 a 12 anos de idade, Goiânia, GO, Brasil. Rev. Saude Publica 1997; 31:4452.

8. Basting RT, Pereira AC, M eneghim MC. Avaliação da prevalência da cárie dentária em escolares do município de Piracicaba-SP, Brasil, após 25 anos de fluoretação das águas de abastecimento público. Rev de O dontologia da U niversidade de São Paulo 1997; 11:287-292.

9. Brasil. Lei Federal ํo 6050 de 24 de maio de 1974 Dispõe sobre a obrigatoriedade da fluoretação da águas em sistema de abastecimento. Diário Oficial da União 1975; 27 jul.

10. Brasil. M inistério da Saúde. Sub-componente fluore tação da água. Programa Brasil Sorridente - a saúde bucal levada a sério. Brasília: Ministério da Saúde; 2006.
11. M urray JJ. 0 uso correto de fluoretos na saúde pública. São Paulo: Santos; 1992.

12. World Health Organization. Fluorides and Oral Health. Geneva: WHO; 1994. [WHO Technical Report Series].

13. Assis GF de, Buzalaf MAR, Faria FAC de, Granjeiro JM, Torres SA, Lara VS, Oliveira DT. M ecanismos biológicos e influência de fatores ambientais na fluorose dentária e a participação do flúor na prevenção da cárie. Revisão de literatura. Rev Fac 0 dontol Bauru 1999; 7:3/4:63-70.

14. Lewis DW, Banting DW. Water fluoridation: Current effectiveness and dental fluorosis. Community Dentistry and Oral Epidemiology 1994; 22:153-158.

15. Narvai PC, Castellanos RA. Prevalência de cárie em dentes permanentes de escolares do Município de São Paulo, SP. Rev. Saude Publica 2000; 2:196-200.

16. Marthaller TM. Water fluoridation results in Basel since 1962: health and political implications. J Publ HIth Dent 1996; 56(5 Spec No):265-270.

17. Chaves M M, Frankel JM, M ello C. Fluoretação de águas de abastecimento público para a prevenção parcial da cárie dentária. Rev Assoc Paul Cir Dent 1953; 2:27-33.

18. Lima FG, Lund RG, Justino LM, Demarco FF, Del $P F A B$, Ferreira R. Twenty-four months of external control of fluoride levels in the public water supply in Pelotas, Rio Grande do Sul, Brazil. Cad Saude Publica 2004; 20:2

19. Maia LC, Valença AM G, Soares EL, Cury JA. Controle operacional da fluoretação da água de Niterói, Rio de Janeiro, Brasil. Cad Saude Publica 2003; 19:1.

20. Brossak GE, MCTique DJ, Kuthy RA. The use of a colorimeter in analyzing the fluoride content of public well water. Pediatric Dentistry 1987; 9:204-207.

Artigo apresentado em 24/08/2007 Aprovado em 08/02/2008 